\title{
Konsep tata ruang permukiman Baluwarti Keraton Kasunanan Surakarta
}

\author{
Tri Hartanto ${ }^{\mathrm{a}^{*}, 1}$, A Bambang Yuwono ${ }^{\mathrm{a}}$
}

a Program Studi Arsitektur, Fakultas Teknik, Universitas Tunas Pembangunan Surakarta

1 email penulis pertama : tri.hartanto23@yahoo.com

\begin{tabular}{ll}
\hline Informasi artikel & ABSTRAK \\
\hline Sejarah artikel: & Penelitian terkait permukiman sudah banyak dilakukan oleh para ahli baik \\
Diterima & di dalam negeri maupun di luar negeri. Permukiman sebagai obyek \\
Revisi & penelitian telah lama dilakukan karena terkait dengan sosial budaya yang \\
Dipublikasikan & berkembang di masyarakat. Penelitian ini memilih lokus permukiman \\
\hline Kata kunci: & Baluwarti, dan fokus penelitian adalah tata ruang permukimannya yang \\
Tata Ruang & memiliki kekhasan tersendiri. Kekhasan tata ruang permukiman Baluwarti \\
Permukiman & yang dimaksud adalah bahwa permukiman ini berbeda dengan \\
Baluwarti & permukiman tradisional lainya karena permukiman ini berada di dalam \\
Keraton Kasunanan & kawasan keraton Surakarta. Dimana keraton Surakarta dikenal sebagai \\
Surakarta & pusat kebudayaan Jawa. Sehingga permukiman tradisional lainya yang \\
& berada di Jawa, tentunya bersumber dari budaya keraton Surakarta. \\
& Paradaigma penelitian adalah Kualitatif dangan metode historical reading \\
dan observasi, sedangkan analisis menggunakan induktif. Kebaharuan dari \\
penelitian ini adalah akan ditemukan konsep tata ruang permukiman \\
Baluwarti yang memiliki kekhasan, dari nilai-nilai tradisi dan budaya \\
Keraton Surakarta Hadiningrat yang kaya akan tradisi dan budaya (budaya \\
Jawa), karena berada di dalam kawasan keraton. Berbeda dengan \\
penelitian-penelitian permukiman yang telah dilakukan sebelumnya \\
dengan lokus penelitian berada di luar keraton. Berdasarkan penelitian \\
yang telah dilakukan bahwa konsep tata ruang Baluwarti merupakan \\
konsep yang dipertahankan dari permukiman ini dibangun, yaitu pada \\
masa Paku Buwana III (1745-1788M) adalah menjaga keharmonisan \\
manusia dengan Tuhan, keharmonisan manusia dengan manusia \\
(masyarakat), dan keharmonisan manusia dengan alam.
\end{tabular}

Key word:

Spatial

Settlement

Baluwarti

Kasunanan Palace

Surakarta

\begin{abstract}
Research related to settlements has been carried out by many experts both at home and abroad. Settlement as an object of research has been carried out for a long time because it is related to the social culture that develops in the community. This study selects the locus of the Baluwarti settlement, and the focus of the study is the settlement layout which has its own peculiarities. The peculiarity of the spatial layout of the Baluwarti settlement in question is that this settlement is different from other traditional settlements because this settlement is located within the Surakarta palace area. Where the Surakarta palace is known as the center of Javanese culture. So that other traditional settlements in Java, of course, come from the culture of the Surakarta palace. The research paradigm is qualitative with historical reading and observation methods, while the analysis uses inductive methods. The novelty of this research is that the concept of spatial planning for the Baluwarti settlement will be found which is unique, from the traditional and cultural values of the Surakarta Hadiningrat Palace which is rich in traditions and culture (Javanese culture), because it is located in the palace area. It is different from the settlement studies that have been done previously with the research locus outside the palace. Based on the research that has been done, the concept of the Baluwarti spatial plan is a concept that is maintained from this built settlement, namely during the period of Paku Buwana III (1745-1788M), it was maintaining harmony between humans and God, harmony between humans and humans (society), and harmony between humans and nature.
\end{abstract}




\section{Pendahuluan}

Isu internasional terkait perkotaan dan permukiman adalah sustainable city dan communities. Dalam skala permukiman isu humanists menjadi topik yang menarik untuk didiskusikan. Permukiman yang humanis tentu tidak dapat terwujud dengan hanya mengandalkan konsep fisik saja, tetapi harus memperhatikan nilai-nilai dasar kemanusiaan. Dimana manusia sebagai mahkluk sosial tidak bisa lepas dalam hubungannya dengan sesama manusia (dimensi horizontal), dan hubungan manusia dengan Tuhan (dimensi vertikal) harus terimplementasikan ke dalam struktur ruang suatu permukiman, sehingga keselarasan hidup akan tercapai. Kemajuan teknologi tidak menjamin kebahagiaan seseorang, karena manusia membutuhkan sosiaalisasi dengan tetangga, saudara, rekan kerja, dan manusia lain.

Bangunan di Baluwarti menunjukan arsitektur tradisional Jawa, terlihat dari bangunan rumahnya yang berbentuk kampung, limasan, dan Joglo, yang masih dilihat hingga saat sekarang. Sebagia besar masyarakat di kampung Baluwarti masih juga memegang teguh dalam hal adat-istiadat, kebiasaan, tata cara dan budaya Jawa (keraton). Kekhasan inilah yang menjadikan permukiman Baluwarti masuk dalam kawasan cagar budaya yang ada di Kota Solo, dan sekalugus merupakan peninggalan yang bernilai sejarah, sesuai Surat Keputusan Walikota madya Kepala Daerah Tingkat II Surakarta Nomor 646/116/i/1997 tentang Penetapan Bangunan dan Kawasan Kuno Bersejarah di Kotamadya Daerah Tingkat II Surakarta. Namun didalam upaya pelestarian kawasan permukiman ini juga memiliki permasalahan-permasalahan sama seperti yang dihadapi di tempat lain. Seperti yang penulis kaji pada tahun 2015, bahwa setidaknya ada lima isu/permasalahan yang dihadapi dalam pelestarian kawasan permukiman, antara lain: a) regulasi, penerapan peraturan dan perundangan di lapangan yang belum terealisasi dengan baik, b) belum adanya konsep yang jelas di dalam pelestarian kawasan, sehingga masyarakat setempat belum menjalankan pelestarian kawasan dengan baik, c) pendanaan, sebagian besar masih bergantung kepada subsidi pemerintah, d) konflik kepentingan, bisa datang dari dalam dan dari luar kawasan pelestarian, dan e) rendahnya partisipasi masyarakat. Terkait dengan permasalahan konsep, konflik kepentingan, dan masih rendahnya partisipasi masyarakat, diharapkan dari hasil penelitian yang akan dilakukan dapat memberikan informasi tentang konsep permukiman ini, yang sarat nilai-nilai kultural keraton yang adiluhung, agar dilestarikan dan dipertahankan untuk generasi masa depan.

\section{Metode}

Permukiman Baluwarti merupakan bagian dari wilayah keraton Kasunanan Surakarta. Konsep hunian di permukiman Baluwarti sangat dipengaruhi oleh konsep dari keraton. Walaupun permukiman Baluwarti dan kedhaton sama-sama berada di njeron benteng (dalam benteng), tetapi keduanya memiliki perbedaan didalam penataan konsep hunian. Konsep hunian di permukiman Baluwarti pada masa pemerintahan PB.III dibuat pengelompokan berdasarkan profesi abdi dalem. Abdi dalem sebagai prajurit Tamtamaastra dikelompokan dalam hunian yang disebut dengan kampung Tamtaman. Abdi dalem sebagai prajurit Carangastra dikelompokan dalam hunian, yang disebut dengan kampung Carangan. Sedangkan abdi dalem sebagai prajurit Wirengastra, dikelompokan dalam satu hunian yang disebut dengan Kampung Wirengan. Di setiap kelompok hunian tersebut dikoordinir oleh seorang berpangkat Tumenggung, yang bertanggung jawab atas kondisi lingkungannya. Ketiga kelompok hunian yang terbentuk mengelilingi kedhaton secara konsentris.

Pola permukiman di dalam lingkungan permukiman Baluwarti, terlihat dari pembagian wilayah, atau daerah hunian tempat tinggal menurut golongan sosial atas-bawah. Para bangsawan dan pejabat tinggi keraton bertempat tinggal pada lokasi yang terletak di pinggir jalan lingkar utama, sedangkan para abdi dalem menempati rumah tinggal mereka di dalam perkampungan. Permukiman abdi dalem di Baluwarti awalnya terdiri dari 5 (lima) kampung, yaitu: (1) Kampung Tamtaman, (2) Kampung Carangan, (3) Kampung Wirengan, (4) Kampung Hordenasan, dan (5) Kampung Gambuhan. Berdasarkan penuturan KGPH Poeger (2016), bahwa lahan yang menjadi cikal bakal permukiman Baluwarti adalah tanah milik keraton, dan diperuntukkan sebagai tempat tinggal sentana dalem dan abdi dalem, dengan status hak pakai (magersari). Sependapat dengan KGPH Poeger, menurut Kanjeng Budaya (2016) maksud lahan ini diperuntukkan sebagai tempat tinggal sentana dalem dan abdi dalem 
adalah dengan pertimbangan bahwa sewaktu-waktu sentana dalem dan abdi dalem, baik itu pangeran, bupati, prajurit, penari, penabuh dan abdi lainnya, jika diperlukan oleh Raja, dapat segera tiba dan menghadap.

Pemilihan metode penelitian memperhatikan metode penelitian yang mampu merumuskan konsep lokal (idiographis) yang tetap terikat dengan konteks tertentu. Dalam hal ini, penelitian tidak hanya bertujuan untuk mengidentifikasi tata ruang permukiman Baluwarti secara fisik, namun berupaya mengidentifikasi konsep yang melandasi perwujudan fisik tata ruang permukiman Baluwarti. Konsep tersebut diyakini dipengaruhi oleh nilai-nilai tradisi dan budaya keraton Surakarta. Konteks dari nilainilai tradisi dan budaya keraton tersebut tidak hanya dapat ditangkap dengan panca indera (sensual) dan logika pikiran (logik), namun dapat pula ditangkap dengan akal budi/perasaan (etik) dan dengan kepercayaan atau keyakinan (transendental).

Adapun metode penelitian yang digunakan adalah Historical Studies dengan membaca sejarah (historical reading). Historical studies digunakan untuk mengetahui konsep awal tata ruang dari permukiman Baluwarti yang dibangun, melalui buku-buku atau babad yang menceritakan kondisi saat itu, dokumen/arsip/majalah/artikel, dan koran, gambar dalam periode saat itu, dan artefak yang masih ada. Sehingga dapat digunakan untuk melihat elemen-elemen tata ruang permukiman Baluwarti yang masih bertahan hingga saat ini. Selanjutnya pendekatan induktif kualitatif dengan wawancara mendalam (indepth interview) digunakan untuk mengungkapkan faktor-faktor yang mempengaruhi masyarakat masih memegang teguh nilai-nilai dari tradisi dan budaya sebagai pembentuk kekhasan tata ruang permukiman tradisional Baluwarti.

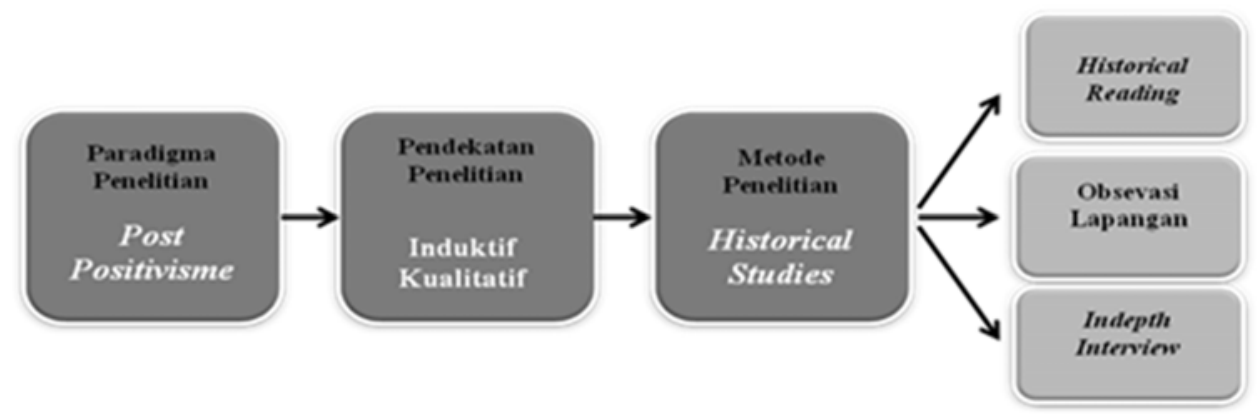

Gambar 1. Paradigma, Pendekatan, dan Metode Penelitian Analisis Penulis

\section{Hasil dan pembahasan}

Menurut Rapoport (1989), pengertian tata ruang merupakan lingkungan fisik tempat terdapat hubungan organisatoris antara berbagai macam objek dan manusia yang terpisah dalam ruang-ruang tertentu. Ketataruangan secara konsepsual menekankan pada proses yang saling bergantung antara lain: (a)proses yang mengkhususkan aktivitas pada suatu kawasan sesuai dengan hubungan fungsional tersebut, (b) proses pengadaan ketersediaan fisik yang menjawab kebutuhan akan ruang bagi aktivitas seperti bentuk tempat kerja, tempat tinggal, transportasi dan komunikasi, dan (c) proses pengadaan dan penggabungan tatanan ruang ini antara berbagai bagian-bagian permukaan bumi di atas, yang mana ditempatkan berbagai aktivitas dengan bagian atas ruang angkasa, serta ke bagian dalam yang mengandung berbagai sumber daya sehingga perlu dilihat dalam wawasan yang integratik.

Sebuah tempat atau ruang tidak homogen tetapi berbeda, membentuk ruang yang bersifat sakral dan profan (Eliade, 1959). Ruang sakral adalah konsepsi tentang ruang dan adanya persepsi atau pandangan tentang sebuah kekuatan yang berasal dari alam, roh maupun Sang Pencipta. Ruang bersifat profan karena dianggap homogen atau netral tanpa perbedaan secara kualitas. Konsep sakral-profan juga dikemukakan oleh Tuan (2008) adanya hubungan ruang dan waktu yang bersifat subyektif dan tidak terukur (timelessness). Ruang pusat (centre) sebagai titik pusat kekuatan berada di tengah (pusat) dan akan melemah pada bagian tepi (pinggir), sebagai konsepsi ruang sirkular terhadap sakral-profan 
(Geertz, 1983). Konsepsi ini ditemui di kota Bangkok, dimana Istana Raja sebagai pusat (centre) kota.

Gambar 2. Konsep

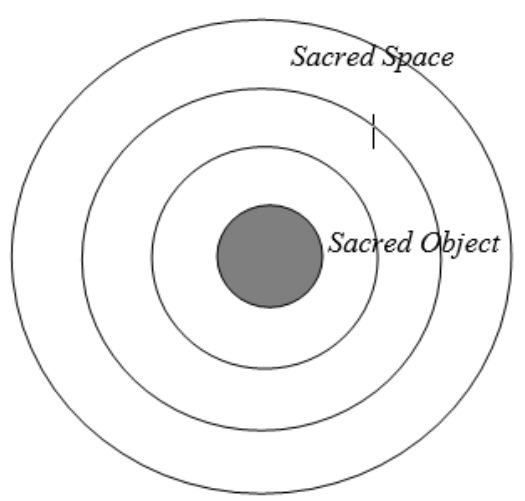

Spirit Pada Permukiman

Sakral Profan Sebagai Ruang

Sumber: Tuan, 2008; Geertz, 1983; Eliade, 1959

Dalam konsep tradisional jawa, orang Jawa menyebut kawasan keraton sebagai nagara atau nagari. Nagara sebenarnya konsep yang sudah sangat lama dikenal di Indonesia dan dianggap sebagai pengaruh Hindu. Nagara sebagai suatu bentuk kekuasaan politis di Indonesia sudah di kenal setidak-tidaknya sejak abad ke-5. Dengan konsep nagara organisasi sosial politik dan ekonomi pemukiman dikelola oleh suatu sistem kekuasaan atas beberapa desa. Sebagaimana dikutip oleh Wiryomartono, nagara adalah daerah tinggal yang dapat dicapai dari desa-desa sekelilingnya tanpa harus melintasi sawah.

Di Jawa selain mengenal konsep nagara dikenal pula konsep kuta. Kedua konsep tersebut pengertiannya sama dimana nagara merupakan kawasan yang didalamnya tinggal seorang raja, sedangkan kuta merupakan kawasan yang lebih umum dimana daerah tersebut tanpa harus dihuni oleh seorang raja. Menurut Wiryomartono, kuta secara harfiah berarti daerah pemukiman yang dilindungi oleh dinding yang dibangun mengeliling menurut bentuk pasagi (persegi). Dinding ini digunakan sebagai garis batas dhalem untuk melindungi teritorialnya sekaligus memberi definisi luar dan dalamnya kehalusan dalam berkrama. Untuk menyebut kuta yang menjadi kawasan tempat tinggal raja (nagara), di Jawa muncul konsep kutagara. Kutagara merupakan kawasan inti dimana berdiri rumah raja (keraton) yang merupakan pusat kekuasaan.

Secara struktural konsep tata ruang Jawa pada periode pra kolonial mengacu pada prinsip mikrokosmos hierarkis (Sunaryo, 2015). Kedua konsep ini mengacu pada prinsipnya bahwa raja adalah pusat dunia (mikrokosmis hierarkis) dan raja sebagai pengatur keseimbangan alam semesta (mikrokosmos dualistis). Penerapan mikrokosmos hierarkis pada penetapan wilayahwilayah yang masuk kepada wilayah pusat (Keraton-Negaragung) hingga wilayah terluar (Mancanegara). Kemudian Soemardjan dalam Gunawan, (2015) menggambarkan bahwa konsep kota dan negara dalam tata ruang Jawa-Mataram berbentuk suatu sistem lingkaran terdalam adalah wilayah paling sakral dari kota/negara, semakin keluar dari lingkaran pusat maka tingkat kesakralan bergerak ke arah profan. Lingkaran terluar dari konsep tata ruang ini adalah mancanegara, yang merupakan wilayah-wilayah otonom, tetapi tunduk dan mengaku kedaulatan Sultan.

Seiring dengan berkembangnya modernisme dengan ciri khas rasionalismenya, maka keyakinan-keyakinan meta-empirik perlahan mengalami pergeseran. Ketidak-mampuan rasio membaca tanda-tanda alam yang tak terindra menggeser sebagian pengetahuan kosmologi pramodern ke wilayah mitos dan mistisisme. Dalam kajian-kajian arsitektur, khususnya di Nusantara, kosmologi dipandang sebagai salah satu faktor pembentuk ruang (Mashuri, 2010; Sumalyo, 2001; Widayat, 2004; Widyatasari, 2002; Wesnawa, 2010; Xu, 1998; dan Kartono, 2005). Ruang sakral-profan, bentuk atap, kolom, tata ruang rumah, permukiman, dan kota adalah wujud konsep-konsep kosmologis.

Pola diagram merupakan pola-pola ruang kota yang terbentuk akibat adanya pengaruhpengaruh dari pelbagai aspek atau aktivitas yang paling menonjol pada suatu kota, seperti: agama atau kepercayaan, politik dan pemerintahan, atau keamanan dan pertahanan, sehingga 
terbentuk pola-pola ruang kota spesifik, seperti: pola melingkar/lingkaran (circles), pola linear, atau pola radial-konsentris. Menurut Kostof (1991), pola melingkar merupakan pola yang dibentuk untuk menunjukkan pemusatan kekuasaan pemimpin (raja) dan untuk mengoptimalkan sistem pertahanan kota. Pola linear merupakan pola menerus yang terbentuk akibat adanya dorongan dari aspek kepercayaan kosmologis, serta aspek topografi fisik dan budaya. Sementara itu, pola radial-konsentris terbentuk akibat adanya pertimbangan keamanan serta untuk mengoptimalkan pertahanan di dalam dan di luar kota.

Pola lainnya yang dikemukakan oleh Kostof (1991) adalah pola papan catur (the grid) atau disebut juga dengan gridiron atau checkerboard, yang merupakan pola (pattern) paling umum digunakan untuk merencanakan sebuah kota (planned city). Menurut Kostof (1991: 99), pola papan catur (the grid) pada umumnya digunakan untuk kota-kota kecil (towns) yang memiliki fungsi utama sebagai pertahanan (defense), pengembangan pertanian (agriculture development), dan perdagangan (trade), serta sebagai simbol pemerintahan demokratis (di Negara barat), serta sebagai simbol pemerintahan absolut (di China dan Jepang).

Beberapa teori dan konsep tersebut yang berhubungan dengan permukiman dan kebudayaan secara umum mengungkapkan bahwa, manusia dalam membentuk wadah atau tempat hidupnya sangat dipengaruhi oleh budaya yang telah berakar dan menjadi bagian yang tidak terpisahkan dalam kehidupannya. Selain itu, aspek sosial menjadi faktor berikutnya yang sangat dipertimbangkan dan biasanya selalu berjalan beriringan dalam proses pembentukan wadah hunian bagi masyarakat tertentu. Aspek-aspek lain seperti iklim, kondisi geografis, dan lain sebagainya akan menjadi faktor yang mengikuti aspek-aspek budaya dan sosial. Tata ruang suatu masyarakat tidak terlepas dari sistem religi atau kepercayaan masyarakat yang bersangkutan. Sifatnya yang paling hakiki dalam kehidupan, maka aspek religi atau kepercayaan ini termasuk sulit untuk berubah, namun menjadi pengaruh dan menjadi landasan dalam perilaku kehidupan lainnya (Permana, 1995: 14).

Untuk mengetahui tata ruang kekhasan tata ruang permukiman Baluwarti dapat dilihat dari elemen-elemen yang menyusun tata ruang permukimannya. Adapun elemen tata ruang permukiman Baluwarti dapat dijelaskan kedalam dua kelompok, yaitu:

\section{a. Elemen Fisik Tata Ruang}

Permukiman baluwarti merupakan bagian dari wilayah keraton Surakarta. Kawasan ini terletak diantara dua beteng, yaitu: beteng cempuri (bagian dalam) dan beteng Baluwarti (bagian luar).

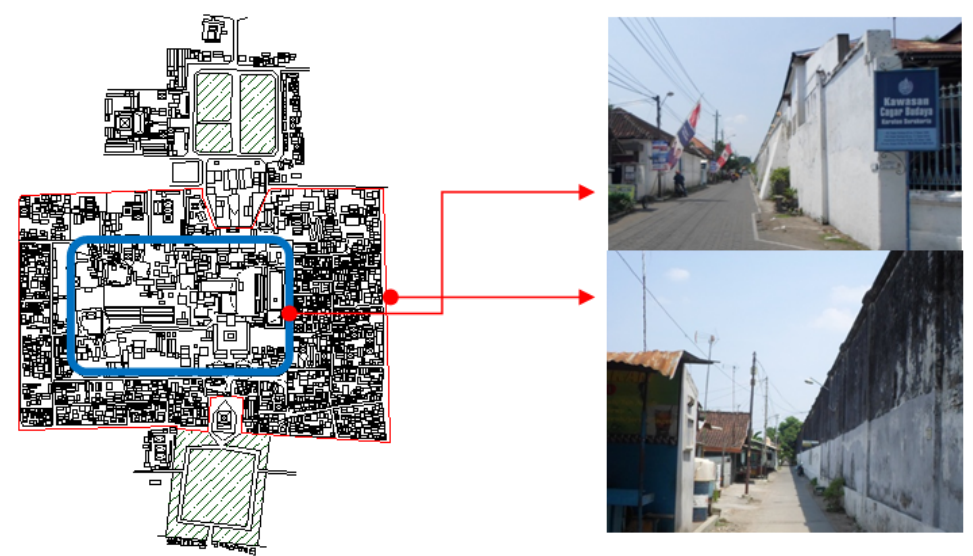

Batas Lahan/Kawasan dalam Tata Ruang Permukiman Baluwarti

Gambar 3. (Sumber: observasi dan analisis)

Beteng cempuri melindungi kedhaton (tempat tinggal raja dan keluarganya), sedangkan beteng Baluwarti melindungi semua yang berada di dalam kawasan Baluwarti, yaitu kedhaton dan permukiman Baluwarti. Pola tata ruang dari permukiman Baluwarti adalah mengelilingi kedhaton secara konsentris. Sehingga sangat jelas bahwa permukiman ini berorientasi tunggal yaitu kearah raja, yang berkedudukan di kedhaton. Adapun akses kedalam kawasan Baluwarti, awalnya hanya ada dua titik, yaitu di bagian Utara yang disebut dengan kori brajanala lor dan 
di bagian Selatan disebut kori brajanala kidul. Kemudian pada masa PB.X akses kedalam dan keluar kawasan ditambah di dua titik yang terletak di samping kawasan sebelah timur yang diberi nama lawang gapit etan dan di sebelah barat yang dikenal dengan lawang gapit kulon.
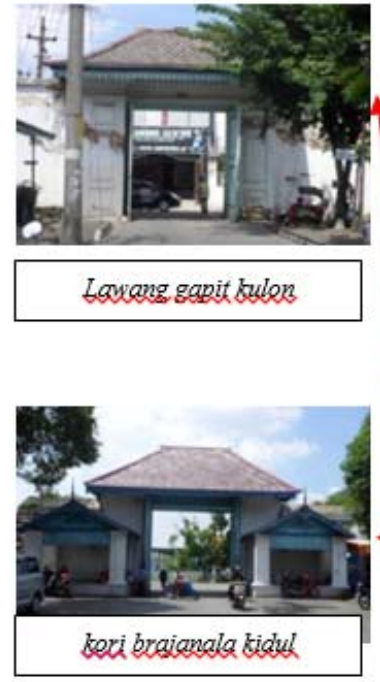

Gambar 4. Akses dalam Tata Ruang Permukiman Baluwarti (Sumber: observasi dan analisis, 2017)

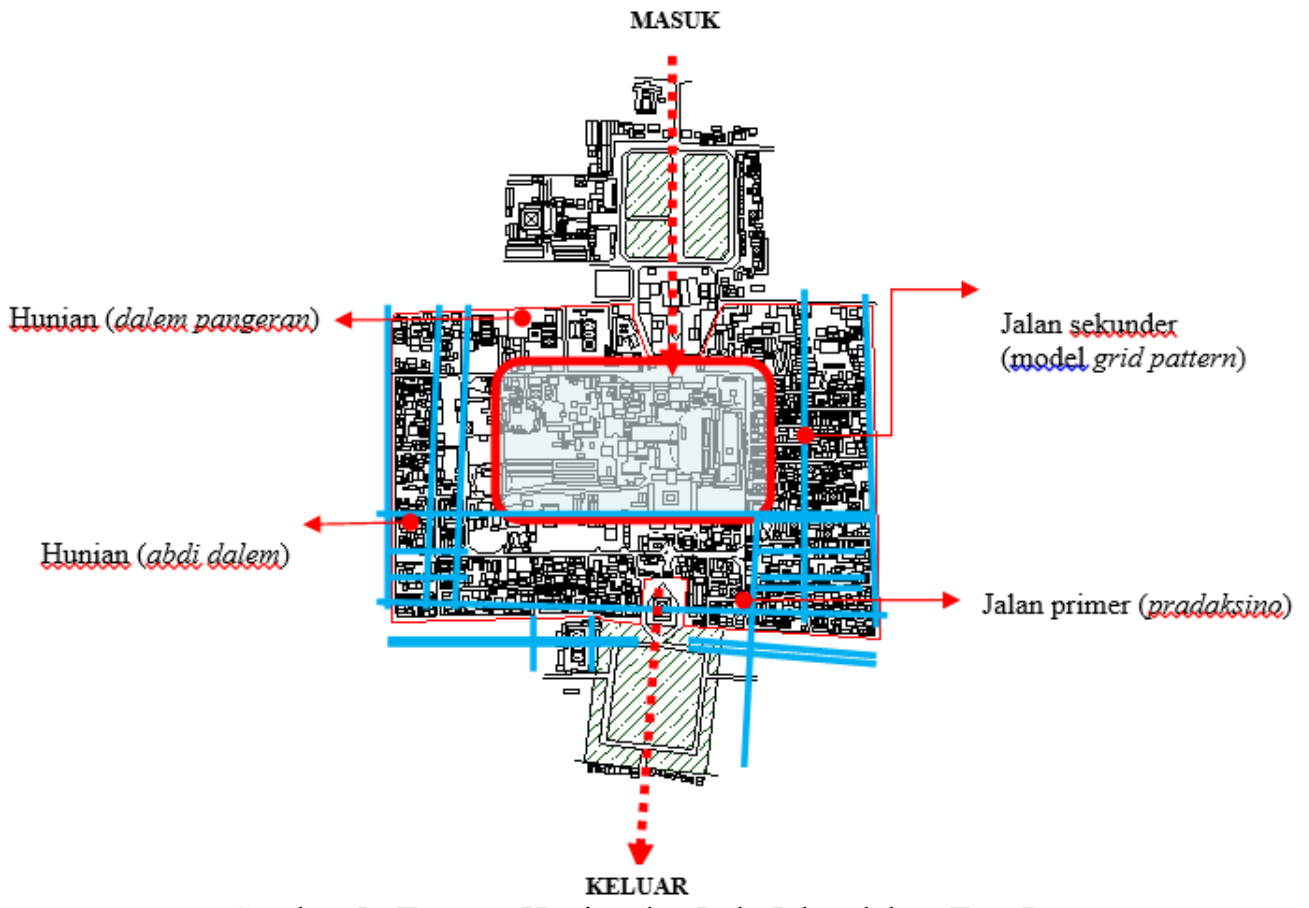

Gambar 5. Tatanan Hunian dan Pola Jalan dalam Tata Ruang

Permukiman Baluwarti

(Sumber: analisis, 2017)

Bentuk dari model permukiman Baluwarti adalah grid pattern, yang terbentuk oleh lahan/kapling permukiman dengan jalan lingkungan yang kecil dan sempit. Dimana jalan-jalan kecil (sekunder) berorientasi pada jalan primer yang lebar dan mengelilingi kedhaton. Pola sirkulasi memutar searah jarum jam, yang disebut dengan pradaksino. Sirkulasi di kawasan permukiman Baluwarti mengikuti tradisi keraton, dimana arah masuk dari Utara, kemudian 
memutar searah jarum jam menuju arah Selatan. Pintu masuk utama adalah kori brajanala lor dan pintu keluarnya adalah kori brajanala kidul. Gambar 10. menjelaskan model permukiman dan jalan lingkungan, serta jalan utama di kawasan permukiman Baluwarti Surakarta.

Berdasarkan artefak yang ada bahwa setiap komplek permukiman terdapat tipe bangunan bentuk rumah Joglo untuk pejabat tinggi, bentuk rumah Limasan untuk pejabat menengah, dan bentuk rumah Kampung untuk rakyat/kawula. Bentuk Kampung lebih banyak dibanding dengan bentuk Limasan, bentuk Limasan lebih banyak dibanding dengan bentuk Joglo. Sehingga dapat diketahui bahwa dalam kehidupan sosial masyarakat saat itu, dalam komunitas permukiman (prajurit) terdapat pemimpin/pejabat tinggi, pemimpin di bawahnya/pejabat menengah, dan abdi dalem/prajurit. Masing-masing memiliki hak dan kewajiban sesuai status dan gelar yang dimiliki yang ditentukan oleh keraton (raja).

\section{b. Elemen Non Fisik Tata Ruang}

Masyarakat di Baluwarti pada umumnya adalah masyarakat etnis Jawa. Hal tersebut dikarenakan bahwa di samping tidak adanya data monografi yang berisi data tentang masyarakat keturunan di permukiman tersebut, juga dapat diketahui dari sejarah Baluwarti sendiri, yaitu bahwa Baluwarti berasal dari bahasa Portugis yaitu Baluarte yang artinya benteng, dan di antara tembok yang mengelilingi Kedhaton dan Baluwarti terdapat daerah tempat tinggal, (Darsiti Soeratman). Baluwarti merupakan tempat tinggal yang dikhususkan bagi para bangsawan, priyayi tingkat tinggi dan para abdi dalem Keraton Kasunanan Surakarta. Priyayi tingkat tinggi seperti Poerwodiningrat dan Mlayakusuma menempati wilayah sebelah Utara keraton, di samping itu juga terdapat tempat tinggal pada prajurit keraton seperti Carangan dan Tamtaman yang menempati wilayah Timur keraton, selain itu juga terdapat tempat tinggal bagi para abdi dalem lain yang tinggal di sekeliling keraton.

Menurut Kanjeng Budaya (2016), setelah keraton selesai dibangun dan Sinuwun PB.II telah menempati kedhaton, raja memberikan tanah di sekitar kedhaton untuk tempat tinggal abdi dalem. Abdi dalem berhak tinggal namun tidak berhak memiliki, dan sewaktu-waktu diminta lagi harus diserahkan kepada pihak keraton, yang disebut dengan magersari. Sistem magersari merupakan elemen non fisik dalam tata ruang permukiman Baluwarti. Dalam perkembangannya abdi dalem yang mendapat tanah tersebut kemudian membuatkan tempat tinggal kepada para kerabat atau pembantu dalam keluarga tersebut. Dan sebagian dari pembantu rumah tersebut jika ingin mengabdi kepada raja, maka pihak keraton akan melihat siapa yang memberi rekomendasi kepada abdi tersebut. Sehingga bila terjadi sesuatu dikemudian hari pihak yang memberi rekomendasi juga harus ikut bertanggung jawab. Kondisi seperti ini berkembang secara terus menerus sehingga permukiman baluwarti semakin padat.

Status dan gelar di dalam kehidupan sosial masyarakat di permukiman Baluwarti saat itu sebagian besar adalah sentana dalem dan abdi dalem, yang bekerja/mengabdi kepada raja. Sehingga hampir semua warga di Baluwarti memiliki gelar yang diperoleh dari raja. Status sosial masyarakat Baluwarti diperoleh secara turun temurun dari garis keluarganya, yaitu status sosial bangsawan, sentana, dan abdi dalem keraton Surakarta. Meskipun nuansa keislaman telah mewarnai simbol-simbol budaya keraton Kasunanan Surakarta, pada kenyataannya perilaku dan sikap keagamaan masyarakatnya masih menampakkan sifat Islam sinkretik. Berbagai kepercayaan pra Islam, seperti kepercayaan terhadap kekuatan pusaka, kepercayaan terhadap roh nenek moyang, kepercayaan kepada makhluk halus, dan upacara ritual pra Islam lainnya merupakan bagian yang tidak dapat dipisahkan dari kehidupan keagaman masyarakat keraton. Tabel 1. menjelaskan kekhasan permukiman Baluwarti dengan permukiman tradisional secara umum, berdasarkan elemen-elemen tata ruangnya adalah sebagai berikut:

TABEL 1. ELEMEN-ELEMEN TATA RUANG PERMUKIMAN BALUWARTI

\begin{tabular}{|c|l|l|}
\hline $\begin{array}{c}\text { Elemen-elemen } \\
\text { Tata ruang }\end{array}$ & \multicolumn{1}{|c|}{ Permukiman Baluwarti } & \multicolumn{1}{c|}{ Permukiman Tradisional } \\
\hline Elemen Fisik & $\begin{array}{l}\text { - Berada di dalam lingkungan keraton } \\
\text { - Dibatasi oleh beteng yang tinggi dan kokoh } \\
\text { (beteng Baluwarti) }\end{array}$ & $\begin{array}{l}\text { - Berada di luar lingkungan keraton } \\
\text { - Batas kawasan tidak terdapat } \\
\text { batas/bangunan yang jelas }\end{array}$ \\
& $\begin{array}{l}\text { - Hunian dikelompokan } \\
\text { - Pola hunian konsentris }\end{array}$ & $\begin{array}{l}\text { - Pola hunian mengelompok } \\
\text { - Tidak ada pengelompokan }\end{array}$ \\
& $\begin{array}{l}\text { - Akses yang terbatas (kori brajanala) } \\
\text { - Sirkulasi (pradaksino) }\end{array}$ & - Sirkulasi bebas ke segala arah \\
& - Makam ki Gede Sala & \\
\hline
\end{tabular}




\begin{tabular}{|l|l|l|}
\hline Elemen Non Fisik & $\begin{array}{l}\text { - Sistem kosmologi, empat arah mata angin } \\
\text { (sedulur papat lima pancer) }\end{array}$ & $\begin{array}{l}\text { - Makrokosmos - mikrokosmos } \\
\text { - Tidak ada sistem magersari }\end{array}$ \\
& $\begin{array}{l}\text { - Sistem magersari } \\
\text { - Status dan gelar } \\
\text { - Religi/kepercayaan semua status dan gelar }\end{array}$ \\
& $\begin{array}{l}\text { - Nilai-nilai tradisi langsung dari sumber } \\
\text { (keraton). }\end{array}$ & $\begin{array}{l}\text { - Nilia-nilai tradisi dari budaya } \\
\text { masyarakat. }\end{array}$ \\
\hline
\end{tabular}

Adapun nilai-nilai tradisi dan budaya keraton yang menjadi elemen pembentuk kekhasan tata ruang permukiman Baluwarti adalah nilai-nilai yang terkandung didalam elemen-elemen tata ruang yang bertahan hingga saat ini. Nilai-nilai ini bersumber dari keraton, dan menjadi suatu hal yang masih dipercaya masyarakat Baluwarti. Berikut Gambar 6. nilai-nilai tradisi dan budaya keraton yang ikut membentuk kekhasan tata ruang permukiman Baluwarti yang masih dipertahankan hingga saat ini.

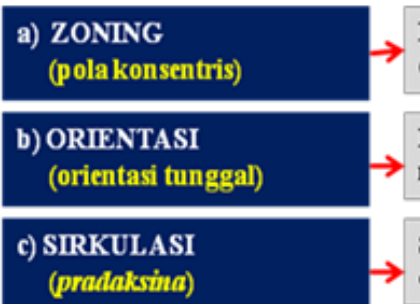

d) AKSIS
(sangkan paraning
dumaadt)

\section{e) POLA HUNLAN} (strata sosial)

f)TATA LETAK BANGUNAN (keselarasan alam)

g) AGAMA dan RELIGI (Tuhan-Raja-Kawula)

h) GELAR dan STATUS (hub.Raja-Kawula)
Kawasan Baluwarti yang dekat dengan kedhaton ( $r a j a)$ dipercaya memiliki nilai-nilai (nilaikesakralan) yang lebih tinggi

Raja dipercaya memiliki kelebihan-kelebihan, karena raja dianggap merupakan manifestasi Tuhan, sehingga orientasikawasan adalah kedhaton (raja).

Sirkulasijalan utama pradaksina, mengandung maksud nengenaken raja, (menghormati dan mengutamak an raja).

Aksis Kawasan berawal dari Kori Brajanala Utara menuju Kori Brajanala Selatan, memilikimakna perjalanan hidup, "dari mana dan kemana tujuan hidup seseorang" (sangkan paraning dumadi).

i) SISTEMMAGERSARI (hub.Raja-Kawula)

Pola Hunian dan Bentuk rumah tinggal dikelompokkan berdasarkan strata sosial (keturuman, pangkat, dan perannya terhadap raja).

Keselamatan hidup dapat dicapai dengan menjaga keselarasan hubungan mikrokosmos dengan makrokosmos (hubungan dengan Tuhan, sesama, dan alam).

Raja dipercaya dan dihormati oleh rakyat/kawula, karena sebagai panata gama, pelindung adat dan tradisibudaya Jawa.

Gelar dan Status, menumjukk an peran, status, dan kedudukan seseorang, yang diperoleh berdasarkan pengabdian yang telah diberikan kepada raja (keraton).

Sistem magersari sebagai iplementasi sifat raja agung binathara, yaitu kewajiban melindungi segenap kawila/ rakyatnya.

Gambar 6. Eksistensi Nilai-nilai Tradisi dan Budaya Keraton Sebagai Elemen Pembentuk Kekhasan Tata Ruang Permukiman Baluwarti 


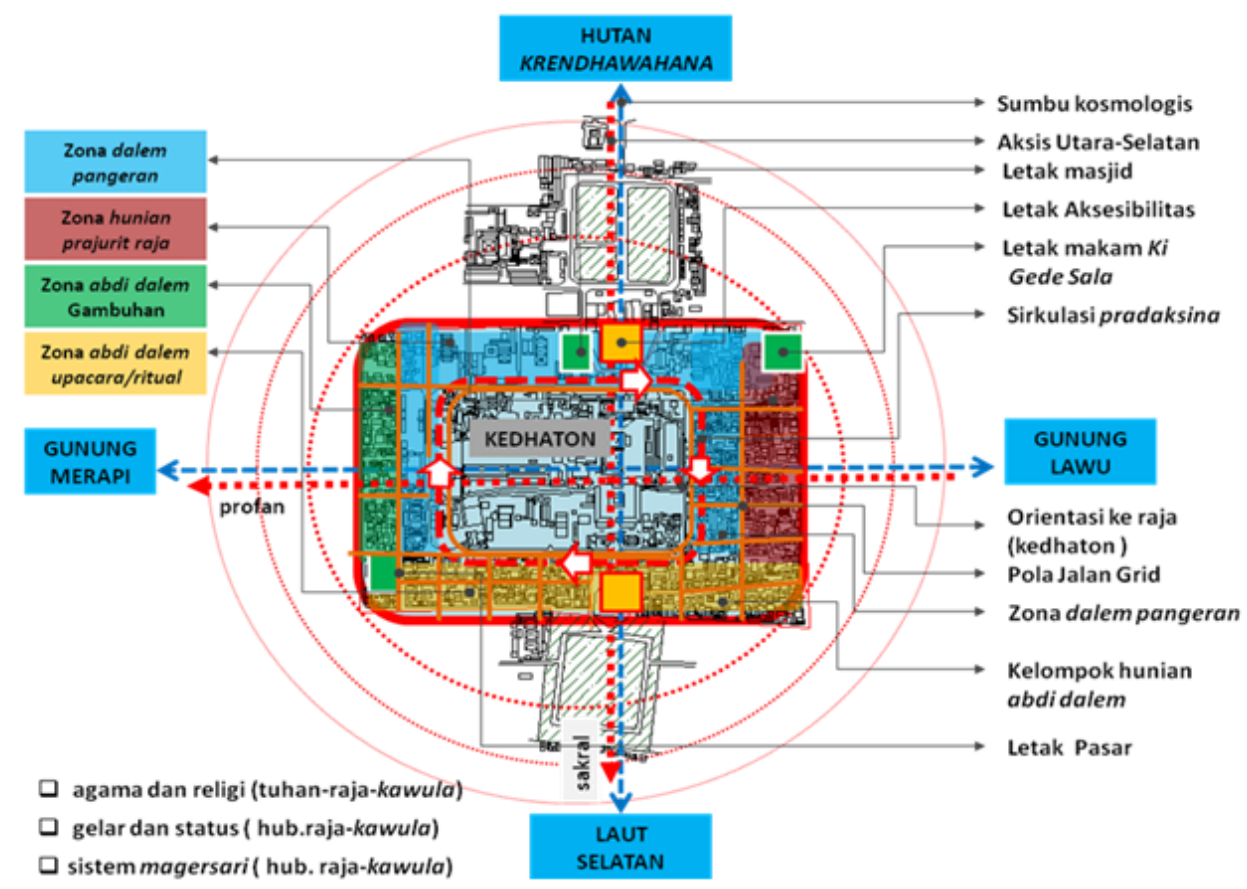

Gambar 7. Eksistensi Nilai-nilai Tradisi dan Budaya Keraton didalam Tata Ruang Permukiman Baluwarti

(Sumber: Analisis, 2017)

\section{Simpulan}

Perwujudan tata ruang permukiman Baluwarti setelah masa PB. III selain dibentuk oleh elemen-elemen fisik juga didukung oleh elemen-elemen non fisik, antara lain: a) agama dan religi; masyarakat Baluwarti memiliki kepercayaan terhadap Tuhan dan juga menghormati raja laksana orang yang memiliki kekhususan, b) gelar dan status; awalnya hampir semua yang bermukim di Baluwarti adalah memiliki ikatan dengan keraton, dengan gelar dan status tertentu. Adapun saat ini sebagian warga sudah tidak memiliki ikatan dengan keraton, dan tanpa gelar serta status, c) sistem magersari; awalnya kawula/rakyat yang tinggal di Baluwarti diberi lahan dan bangunan oleh raja (keraton) dengan system magersari, dimana warga berhak menempati namun sewaktu-waktu tanah dan bangunan dikersake sinuhun maka harus dikembalikan tanpa syarat. Kondisi sekarang tanah dan bangunan sebagian sudah diperjualbelikan tanpa sepengetahuan keraton (raja).

Tata ruang permukiman Baluwarti yang dibangun pada masa pemerintahan Paku Buwana III (1749-1788 M) hingga saat ini (masa Paku Buwana XIII) masih dipertahankan oleh masyarakat Baluwarti. Kebertahanan tata ruang permukiman Baluwarti tidak terlepas dari keberadaan benteng Baluwarti dan konsistensi sebagian besar masyarakat Baluwarti yang masih memegang teguh nilai-nilai tradisi dan budaya keraton sebagai pandangan hidup (way of life) dalam kehidupan sehari-hari. Hal ini didorong oleh keinginan terciptanya keselarasan didalam kehidupan dunia hingga akherat, dengan tetap menjaga hubungan timbal-baik dengan Tuhan, hubungan timbal-baik sesama manusia, dan hubungan yang baik dengan lingkungan sekitar. Keselarasan ini bisa dicapai dengan menjalankan upaya-upaya sebagai berikut: (a) melestarikan tradisi dan budaya leluhur; manifestasi dari kepercayaan/religi masyarakat Baluwarti, (b) menciptakan (rasa) keamanan; manifestasi dari sistem magersari, (c) mengabdi (ngalap berkah) kepada raja/keraton; manifestasi dari status dan gelar peparing dalem. 


\section{Referensi}

Achmad, S,Wintala. 2016. Babad Giyanti: Palihan Nagari dan Perjanjian Salatiga, Araska, Yogyakarta

Budihardjo, Eko. 1997. Jati Diri Arsitektur Indonesia. Alumni, Bandung.

Creswell, John. 2014. Penelitian Kualitatif Dan Desain Riset. Pustaka Pelajar. Yogyakarta

Doxiadis, CA, 1974. Action for A Better Scientific Aproach to the Subject of Human Settlements : The Anthropocosmos Model, Ekistics, 229, 405-412.

Hardiyanti, Nurul Sri dkk. 2005. Studi Perkembangan Dan Pelestarian Kawasan Keraton

Kasunanan Surakarta, jurnal Dimensi Teknik Arsitektur Vol. 33, No. 1, Desember: 112 - 124

Mas Ngabèi Prajaduta, dkk. 1939. Pustaka Sri Radyalaksana, Copyright (C 2011-13 Yayasan Sastra Lestari. Surakarta

Moedjanto, G.1987. Konsep Kekuasaan Jawa, Penerapannya oleh Raja-raja Mataram, Kanisius, Yogyakarta.

Muhajir,Noeng, 2007, Metodologi Keilmuan, Paradigma Kualitatif, Kuantitatif, Dan Mixed. Rake Sarasin, Yogyakarta.

Purwadi, dkk. 2008. Kraton Surakarta: Sejarah, Pemerintahan, Konstitusi, Kesusastraan, Dan Kebudayaan. Panji Pustaka, Yogyakarta.

R.Ng. Prajaduta dkk, 1939. Pustaka Radya Laksana, Budi Utama, Surakarta, Copyright (C 2011-13 Yayasan Sastra Lestari.

R.M. Sajid. 1984. Babad Sala, Rekso Pustoko Mangkunegaran, Solo

Radjiman. 2011. Sejarah Mataram Kartasura sampai Surakarta Hadiningrat, Krida Surakarta.

Ronald, Arya, 2005. Nilai-nilai Arsitektur Tempat tinggal Tradisional Jawa, Gadjah Mada University Press, Yogyakarta.

Santoso, Soewitto, 2003. Babad Tanah Jawi (Galuh Mataram), Dewan Penyantun Sekolah Tinggi Seni Indonesia, Surakarta.

Sholikhin, Muhammad. 2010. Ritual Dan Tradisi Islam Jawa, Narasi, Yogyakarta.

Simuh, 1999. Sufisme Jawa: Transformasi Tasawuf Islam ke Mistik Jawa, Yayasan Bentang Budaya, Yogyakarta.

Soeratman, Darsiti, 1989. Kehidupan Dunia Keraton Surakarta 1830-1939, Taman Siswa, Yogyakarta

Straus, A \& Corbin, J. 2015. Dasar-dasar Penelitian Kualitatif: Tatalangkah Dan Teknik-teknik Teoritisasi Data, Pustaka Pelajar, Yogyakarta

Subanar, G. Budi. 2010. Manunggaling Kawula-Gusti Dalam Transisi; Potret Dunia Jawa dari Yogyakarta. Dalam kumpulan essai "Sesudah Filsafat", cet. 5 Kanisius, 2010), Yogyakarta

Sumantri, 2002.Simbolisme Dalam Upacara Kirab Pusaka Satu Suro Kraton Kasunanan Surakarta Hadiningrat, F. Agama UMS Surakarta.

Yayasan Pawiyatan Kabudayan Karaton Surakarta. 2004. Karaton Surakarta, Buku Antar Bangsa, Jakarta, Indonesia. 